\title{
INTERCULTURALIDADE E GEOGRAFIA: UM DEBATE ESPACIAL DAS RELAÇÕES CULTURAIS
}

\author{
Benhur Pinós da Costa* \\ Universidade Federal de Santa Maria**
}

Resumo: 0 texto discute a relação entre culturas, ou interculturalidade, na perspectiva da Geografia humanista, enfocando, principalmente, a fenomenologia e o existencialismo. Insere, também, elementos teóricos e conceituais das Geografias feministas. O objetivo principal é discutir as relações e os distanciamentos cotidianos de sujeitos portadores de cultura e identidade, que reflete no preconceito e na discriminação vivida no dia a dia das relações nos diferentes espaços sociais. Entende, assim, os espaços relacionais cotidianos como lugares de encontro de diversidades de sujeitos portadores de cultura cujos corpos já se definem como interseccionais e, assim, híbridos de cultura. Propõe uma pedagogia geográfica de construção de espaços de reconhecimento das diferentes culturas a partir da evidência existencial da interculturalidade, já contida nos corpos em relação.

Palavras-chave: Geografia. Interculturalidade. Interseccionalidade. Cotidiano.
INTERCULTURALITY AND GEOGRAPHY: A SPATIAL DEBATE ON CULTURAL RELATIONS

Abstract: The text discusses the relationship between cultures, or interculturality, from the perspective of humanistic geography, focusing, mainly, on the phenomenology and existentialism. It inserts, also, theoretical and conceptual elements of feminist geographies. The main objective is to discuss the daily relations and distances of subjects with culture and identity, reflecting the prejudice and discrimination in the day-to-day relations in different social spaces. Therefore, considers the everyday relational spaces as meeting places of subjects with cultural diversities whose bodies already are defined as intersectional and, thus, hybrid culture. It proposes a geographical pedagogy construction recognition spaces of different cultures from the existential evidence of interculturalism, as contained in the bodies in relation.

Keywords: Geography. Interculturality. Intersectionality. Everyday. 


\section{Introdução}

Este artigo se propõe a debater a importância de se discutir o preconceito cultural na atualidade e a dificuldade de se estabelecer uma ética realmente democrática perante as relações cotidianas, principalmente no aspecto de se colocar "no lugar do outro" e de se pensar a si mesmo como um produto restrito de experiências que impedem a possibilidade de sentir e entender as diversidades contidas no espaço social. Procura, assim, colocar algumas questões em debate para tentar construir uma possibilidade metodológica e prática de entendimento sobre o "outro" e sobre a diferença, tão importante hoje na prática cotidiana e nas possibilidades de educação sobre a diversidade. Para isso, discute a relação entre culturas, ou interculturalidade, na perspectiva da Geografia humanista, enfocando, principalmente, a fenomenologia e o existencialismo. Insere ao debate, também, elementos teóricos e conceituais das Geografias feministas.

O texto propõe uma pedagogia do reconhecimento das diferenças culturais a partir das evidências existenciais da interculturalidade e da interseccionalidade contidas nos sujeitos comuns. Entende, assim, os espaços relacionais cotidianos como lugares de encontro de diversidades de sujeitos portadores de cultura cujos corpos já se definem como interseccionais e, assim, híbridos de cultura. A proposta metodológica e pedagógica, na Geografia, remete ao ideal de desconstrução dos espaços cotidianos como fixos e munidos de determinada identidade fundante, enfatizando as formações espaciais instáveis pelo encontro de diferentes sujeitos, munidos de diferentes culturas, cujos corpos já se apresentam como evidência das interculturalidades.

\section{Uma discussão sobre os processos culturais contemporâneos}

Partimos do pressuposto de que a sociedade contemporânea se apresenta e representa uma diversidade de sujeitos e grupos sociais e que essas diversidades fundam e são fundadas por diferentes contextos e atributos culturais. Queremos debater esta "situação" contemporânea urbana que pode ser entendida como construída por um emaranhado de culturas representado por uma diversidade de grupos culturais urbanos (Oliven, 1987), cujos atributos, éticas e estéticas se constroem justamente pelo constante contato e presença próxima do "outro", que não necessariamente se constitui em uma integração e em uma mútua aceitação.

Podemos entender a cidade contemporânea com um emaranhado de culturas, cujos atributos destas
- de culturas locais e culturas não locais, de culturas hegemônicas e culturas não hegemônicas, marginais e subalternas - sobrevivem em processos de construção e reconstrução muito dinâmicos (Geertz, 1989). 0 entendimento sobre as culturas remete tanto à perspectiva da tradição, como sendo fechadas e confinadas em um conjunto de valores, mitos e rituais que fixam uma identidade diferencial aos sujeitos; como por um aspecto dinâmico transformador - cujas tais formas de se mostrar (estéticas) e de agir (éticas), articuladas com certas atividades rotineiras e/ou ações grupais, que ligam expressões de corpos e crenças intersubjetivas (rituais contemporâneos), representam algo não exatamente diferente de outro conjunto cultural. Esta ideia sobre o dinamismo dos processos culturais evidencia suas construções e representações mistas e hibridas (Canclini, 1998), que ao mesmo tempo se afastam e se aproximam da alteridade em proximidade.

0 entendimento das culturas urbanas, como dinâmicas e constituídas de processos de transformação e reordenamento de seus atributos, é fundamental para entender a sociedade contemporânea atual, principalmente por observar que os efêmeros "fundamentalismos culturais", que repercutem em ações discriminatórias de certos sujeitos, são, na verdade, contextuais e situacionais. No entanto, esses pequenos e efêmeros "fundamentalismos culturais" existem e ocorrem muito sutilmente perante as relações sociais. Estes emergem em determinadas situações cotidianas e geram danos à formação eà socialização de determinados sujeitos, principalmente quando observamos as rígidas e retrógradas ações e concepções de alguns jovens na atualidade, que, muitas vezes, repercutem em relações discriminantes e repletas de preconceito.

Nesse sentido, ao mesmo tempo em que a sociedade contemporânea é constituída por um processo de constante transformação cultural - de diversificação de pequenas formas de intersubjetividades e de partilhamento de rituais e formas de expressão em processos de agregação de atributos culturais de outras culturas, por contato e proximidade e/ou por intermédio de ações e divulgações midiáticas sobre comportamento e estética, produzindo híbridos culturais como "terceiras culturas" (Featherstone, 1995) -, pequenas e cotidianas formas culturais se apresentam ainda fechadas, separando e negando o outro, mesmo ele estando em proximidade e em contato.

Neste contexto cultural dinâmico e híbrido, a ideia do fechamento cultural se processa tanto pela negação e pelo preconceito disposto em ações banais de não aceitação perante a constância dos contatos com a diversidade cultural - gerando interações regidas pela discriminação de um determinado sujeito, que reforça os padrões culturais do e perante o grupo de pertencimento 
- quanto por ações de "estranhamento" e banalização sobre a presença e a ação do outro. Fortuna e Silva (2002) afirmam que a diversidade cultural urbana apresenta um novo sujeito que não é o diferente, mas o "estranho", ou seja, aquele que representa tudo aquilo que me identifica e, ao mesmo tempo, tudo aquilo que me diferencia. 0 estranho é um híbrido cujos atributos "eu posso" repudiar, mas que conheço porque é demasiadamente recorrente em virtude da proximidade cotidiana. Em relação ao estranhamento, é comum atitudes de "indiferença quanto à diferença", ou atitudes blasés, ou, então, formas de "tolerância negativa": aceitar a existência da diferença, mas não manter contato - deixá-la que passe, que se mantenha próxima, mas que isso não gere a relação mútua ou a troca de experiências. Assim, não há exatamente um processo de aprendizado e de se colocar nas situações e "no lugar do outro", existem processo de "laterização" cultural, de proximidade, mas nunca de troca de experiências. Sendo assim, mesmo elas sendo muito dinâmicas e formadas por processos de hibridização, as culturas se apresentam em um novo contexto de fechamento e de negação do outro.

\section{As possibilidades teóricas para conceber 0 diálogo entre culturas}

São nesses sentidos que na atualidade se apresentam as discussões sobre possibilidades de se produzirem teorias e ações práticas que promovam o diálogo entre culturas. Segundo Groff e Pagel (2008), o multiculturalismo é um termo que designa a existência de várias culturas em um determinado espaço, sem que ocorra a predominância de qualquer uma delas. Nessa ideia, as diferentes culturas devem conviver de forma harmoniosa em um contexto de reconhecimento e aceitação sobre as diferenças. No entanto, Boaventura Santos (2003) nos mostra como é complicada a aceitação sobre as ideias do multiculturalismo, principalmente porque ele é encarado como formas de, justamente, manter o domínio de uma cultura em relação a uma diversidade de outros "minoritários". Segundo esse autor, o multiculturalismo é criticado por setores conservadores porque geraria a fragmentação da sociedade, sendo uma ofensa e um perigo a ordem social construída historicamente. Por outro lado, por setores progressistas, o multiculturalismo é visto como uma forma de manter a diferença em seu lugar (em guetos) e ele esconde as desigualdades construídas historicamente. O "pretenso diálogo" é estabelecido pela ação e a linguagem dos setores hegemônicos da sociedade, cujos propósitos pacíficos da ação multicultural geram a manutenção dos poderes e a possibilidade de os marginais serem acoplados aos objetivos sociais dos poderosos.
Em sua demonstração sobre diferentes formas de multiculturalismo, MacLaren (1997) observa que existem teorias (intelectuais) e práticas (no debate e ação política e na construção da legislação) que transitam tanto entre ações de assimilação da diferença para manter intactos valores hegemônicos de uma sociedade - como formas de se ver na história das relações sociais processos de manutenção da desigualdade econômica e cultural -, assim como processo de lutas de reconhecimento sobre as necessidades e a busca de direitos para certas "minorias". Esse autor, ao falar sobre multiculturalismo crítico ou de resistência, aborda a necessidade de se pensar as neutralidades de classe, de etnia, de gênero e de sexualidade que permeiam os discursos sobre multiculturalismo e da necessidade de se pensar os processos que mantém certas visões de mundo, como hegemônicas, que naturalizam os sentidos de ser e estar em sociedade.

Claros e Viaña (2009) problematizam a ideia da possibilidade de diálogos de culturas, uma vez que, para ocorrerem, necessitam da retomada de consciência sobre aspectos limitadores das culturas: pois todos os conceitos e elementos simbólicos de uma cultura só podem ter significado em relação à cultura em que aparecem. É nesse sentido que os processos referentes à interculturalidade, ou o diálogo de culturas, referem-se à necessidade de se criarem espaços de comunicação entre culturas diferentes, criando possibilidades de ação no sentido de promover o entendimento mútuo de determinadas ideias que partem de diferentes sistemas de sentidos culturais. As ações representam, então, processos de tradução. Mas como produzir tal tradução em lugares e conjuntos de ações que estão separadas do contexto interacional das ações práticas de determinadas culturas? Será que a criação de espaços de diálogos de cultura é eficaz quando apresenta somente representações sobre processos culturais de uma cultura ou outra, sem estarem imersas em sistemas de ações e formas simbólicas que guiam estas ações práticas no dia a dia dos acontecimentos entendidos e representados pela diferença cultural?

Gadamer (apud Taylor, 2000) também nos ensina que o "objetivo da compreensão do outro não deve superar nosso ponto de vista nem fugir dele a fim de 'entrar' no outro". Isso vai de encontro à postura crítica proposta por Taylor (1997), que nega a perspectiva de neutralidade, ou seja, o conhecimento do mundo vivenciado a partir da terceira pessoa ou o sujeito neutro baseado nos padrões da racionalidade e da evidência. Para Taylor (2000) e Mattos (2006), "todos nós dispomos de condições de inteligibilidade de nossa cultura que estão vinculadas a nossa compreensão sobre nossas vidas", assim estas nossas compreensões moldam nossos juízos. É exatamente nisso que temos que prestar atenção e fundar nossos pensamentos, se quisermos estabelecer 
um diálogo ético com o outro e, assim, cunhar uma forma de inteligibilidade que funde o "nós", como resultado da relação sem perdas e de compreensão entre "eu" e "outro". Assim, o processo de compreensão do outro envolve uma comparação com minha visão de mundo e de articular os contrastes entre compreensão deles e da minha, refletindo sobre o que me perturba na perspectiva do "deles" e, então, estabelecer o esforço de relativizar os bens que me são caros. O exercício implica a compreensão sobre "eu" pelo contraste do "outro", e isso deve se encaminhar para a alteração da compreensão sobre "eu" mesmo.

É nesse sentido que Claros e Viaña (2009) entendem que o diálogo de culturas não pode ser estabelecido por uma mediação de qualquer tipo de universalidade que sirva de medida comum entre as culturas. Esta crítica concorda com a ideia da neutralidade da formação histórica de um sistema simbólico constituído pela cristandade e pela branquidade que constitui a moral e o direito ocidental (MacLaren, 1997). O diálogo cultural deve criticar qualquer medida neutra que tenda a criar uma relação entre duas culturas, pois isso implicaria a manutenção das hegemonias do pensamento constituído pela branquidade, pela cristandade, pela heterossexualidade, pela masculinidade e pelas noções de individualismo e liberdade tipicamente burgueses. Uma possibilidade de diálogo entre culturas requer uma atenção aos aspectos comuns dos sistemas simbólicos hegemônicos que oprime culturas subalternas, para, assim, entender que entre as diferenças existe unidade justamente nos sentidos e processos que as tornam subjugadas e marginais determinados sujeitos. 0 reconhecimento sobre o "outro" recai no reconhecimento sobre como o outro é oprimido assim como sou "eu".

0 diálogo entre culturas não se coloca em relação a mecanismos universais de possibilidade de existência das diferentes culturas, mas do reconhecimento sobre como esses mecanismos são construídos por bases culturais, políticas e econômicas hegemônicas. Essas hegemonias mantiveram historicamente dominadas $\mathrm{e}$ caladas determinadas culturas, colocando os "fracos" em conflito, no sentido de que estes conflitos "entre os fracos" são importantes para manter escamoteados e neutros os reais sentidos de suas marginalidades sociais. 0 reconhecimento sobre a hegemonia das neutralidades culturais, contidas nos parâmetros morais e legais da sociedade, gera um reconhecimento sobre como outros também são atingidos pela supressão de seu direito de existência, de ação e de expressão. Entre alguns aspectos marginais de determinada cultura, outros aspectos de outras culturas também são marginais e, assim, caberia reconhecer sobre que aspectos de marginalização ambas as culturas são atingidas, como um processo de reconhecimento sobre aquilo que marginaliza, cujo resultado pode culminar no reconhecimento mútuo entre marginalizados.

\section{As discriminações e os possíveis diálogos culturais se dão entre sujeitos portadores de cultura}

Temos que perceber que quem é atingido por atos discrimitários são os sujeitos que são portadores de cultura. A cultura marca o sujeito e o sujeito comporta a cultura em suas expressões, em seu corpo e em suas formas de agir e pensar. 0 sujeito portador de cultura se apresenta como uma alteridade frente a outro sujeito portador de outra cultura. Essa alteridade se apresenta como "diferente" ou como "estranha". A diferenciação torna-se uma graduação mais ampliada de alteridade (o que separa e diferencia "eu" do outro). 0 estranhamento é uma graduação confusa, pois está relacionado não somente àquilo que diferencia mas também àquilo que aproxima, típicas dos processos culturais híbridos na contemporaneidade contemporânea. No entanto, podemos pensar em três aspectos de trânsito de relações culturais.

O primeiro trânsito se apresenta na configuração de relações em contextos espaciais marcados por padrões de interações sociais formais, funcionais e mais rigidamente marcados quanto a formas morais universais. Nesses contextos, o sujeito representa papéis sociais e manipula "personas" (máscaras) que camuflam alguns atributos identitários compartilhados de algum grupo cultural a que pertence (salientamos que os sujeitos fragmentam suas relações em múltiplas possibilidades de trânsito entre grupos culturais e apresentam identidades múltiplas que podem ser ativadas e desativadas pela permissividade relativa do social). As relações nesses contextos são representações cínicas que escondem suas identidades privadas (Goffman, 1996).

O segundo trânsito se conduz em processos espaciais de isolamento cultural e formação de guetos que protegem a intimidade cultural e o anonimato dos sujeitos culturais frente a uma universalidade externa de padrões éticos e estéticos regidos pelas instituições sociais. Nesses lugares, o fechamento cultural é maior, mas pode haver trânsito de sujeitos que procuram experimentar certas sensações estéticas e afetivosexuais.

0 terceiro trânsito refere-se a regiões urbanas nas quais ocorrem relações de proximidade (Fortuna; Silva, 2002) entre diferentes grupos culturais. Tais grupos estão separados, mas, ao mesmo tempo, muito próximos, e os processos de fechamento e marcação de cultura podem ser: mais fortes, pela necessidade de se mostrar aos outros e marcar uma diferença; ou menos forte, pela possibilidade do trânsito e da experimentação da outra cultura, nem que seja pela possibilidade de passar e ver (certo fetichismo ou voyeurismo cultural) sem efetivamente participar. 
O primeiro trânsito é marcado pela representação e pela necessidade de esconder aspectos da identidade pessoal em espaços típicos das relações formais das instituições sociais universais da sociedade (família, trabalho, escola etc.). Algumas instituições sociais tornam mais rígidas a manutenção de aspectos formais estéticos e éticos, como o trabalho, por exemplo. Outras são mais permissíveis e, inclusive, podem se transformar no terceiro tipo de trânsito cultural, como espaço de proximidade cultural, como a escola, por exemplo.

Neste trânsito as relações se complicam quando o sujeito não pode esconder completamente atributos de uma identidade estigmatizada em contexto (Goffman, 1988). O sujeito portador de atributos estigmatizados é pouco propenso à participação, a não ser que a administração institucional formal desenvolva práticas e políticas relacionadas a ações afirmativas da diferença na contemporaneidade. A visibilidade sobre a identidade pessoal que se apresenta como estigmatizada perante as relações sociais pode apresentar diferentes níveis de aceitação ou negação aos sujeitos, e isso depende das qualidades das interações estabelecidas no contexto institucional. No entanto, mesmo que o sujeito se deixe mostrar a partir de algo diferente e não totalmente aceito, sua presença ao contexto interacional somente poderá ser aceita se ele assumir certas posturas éticas e estéticas ditadas pelas formas de relações do lugar. Nesses contextos, as relações podem se complicar em virtude das intrigas e da concorrência estabelecida. $\mathrm{Na}$ escola, por exemplo, grupos de diferentes identidades juvenis podem se formar entre a normalidade e a moral uniforme estabelecida (nas relações entre alunos e professores). Nas relações entre alunos e alunos outras questões subterrâneas às relações formais entre professores e alunos se constroem no sentido de pautar e intensificar as diferenças e as relações discriminatórias e preconceituosas. Nas relações entre professores e alunos as intimidades identitárias dos professores podem gerar confusões sobre os atos de avaliar e julgar o aluno, gerado por preconceitos calados e por atos sutis de discriminação.

O segundo trânsito cultural é marcado por preconceito e discriminação quanto àquele diferente que quer experimentar a cultura do outro, chamado geralmente de "turista" cultural. 0 trânsito do outro ao gueto produz um sintoma de necessidade de ver no outro algo que possibilite sua imersão às práticas culturais. Inúmeros testes são feitos para avaliar suas performances convenientes às interações. Isso gera um fascínio sobre o diferente que se apresenta a participar, mas também uma série de ações de repúdio quanto a suas formas diferentes de agir e de se mostrar, tornando o sujeito diferente isolado no lugar e muito propenso a "chacota" e a retaliação. São os fatores estéticos do sujeito diferente que ora provocarão fascínio sobre a diferença e intenso assédio ou a discriminação exacerbada, como contrário extremo.

0 terceiro trânsito pode se apresentar como o mais problemático em relação à discriminação, pois a proximidade gera sentimentos de exacerbação da diferença e proteção extrema entre componentes de um grupo cultural. A proximidade se apresenta como um fetichismo sobre a sensação de perceber a diferença, mas também por um fascínio de marcá-la. A possibilidade de proteção individual no grupo assegura alta marcação da diferença cultural frente outros. Isso gera a desqualificação cultural dos outros, cujas ações se produzem pela "falação" maldosa e até o choque violento entre grupos. Entre grupos de proximidade, diferentes sujeitos sozinhos transitam não marcando nenhuma outra estética cultural, como se fossem fetichistas pelo experimento e a sensibilidade quanto às diferenças. Esse tipo é muito comum na cidade contemporânea, caracterizado pelo flaneur em Baudelaire (apud Benjamin, 2004), sendo aquele sujeito que se fascina pelas intensidades das cores e das multiplicidades de formas de encontros e expressões de sujeitos e grupos urbanos. O flaneur transita e ora agrega-se a um experimento ou outro, mantendo seu intimismo que é condensado por múltiplas sensações.

As questões de interculturalidade apresentam a perspectiva dos sujeitos munidos de culturas. Entendemos esses sujeitos numa perspectiva plural, pois é "um múltiplo" que transita por diferentes contextos, ativando e desativando diferentes atributos identitários. Esse processo está relacionado com sua intimidade e sua capacidade de escolher e de identificar-se (ou não se identificar) com certas sensações culturais. Além disso, temos de pensar também as perspectivas de sujeitos que são mais ou menos impregnados de certas condições culturais, formados menos ou mais rigidamente por certas formas de pensar, de se mostrar e de agir em sociedade. A perspectiva da formação cultural pode tornar mais rígidas ou menos rígidas as perspectivas interacionais dos sujeitos quanto às diferenças. Quanto mais impregnado em relação a uma determinação ação sociocultural, menos permeável à diferença este sujeito será. Somos seres culturais, e, quanto mais impregnados de certas concepções apreendidas na cultura, menos seremos abertos às possibilidades de interação com a diversidade. Antes de sermos, somos nada (Sartre, 1997). Sendo algo, somos abarcados por um "práticoinerte", ou um conjunto de representações que geram ações, identificações e interações naturalizadas e tidas como normais em que não nos preocupamos em entender suas genealogias e seus porquês. Somos alienados em nossa cultura, formados e socializados nela, e este processo tende a tornar nossas concepções restritas sobre a diversidade de coisas e de outros seres do mundo. "Sendo algo", somos o protótipo da alienação. 
"Sendo nada", somos abertos a novas possibilidades. Então, quem sabe não seria o momento de aprendermos a "ser nada"? Quem sabe não seria o momento de entender "por que somos"? Como nos formamos? De onde e como surgimos como somos?

Claros e Viaña (2009) nos desafiam em pensar ao mesmo tempo a liberdade do sujeito e a comunicação de sentidos entre estruturas (culturais diferentes). Segundo eles, a liberdade do sujeito é a condição da possibilidade de comunicação entre estruturas culturais diferenciadas. Segundo Fornet-Betancourt (apud Claros; Viaña, 2009, p. 92) "a subjetividade não está totalmente determinada pela estrutura cultural". Esta possibilidade de liberdade dos sujeitos em relação aos determinantes culturais é vista em Parsons (apud Claros; Viaña, 2009) e Goffman (Tedesco, 2003), no entendimento sobre o interacionismo simbólico, na qual a sociedade é um conjunto de microinterações estruturadas pelas negociações dos sujeitos em relação, cuja estruturação cultural condiciona cenários, papéis a serem exercidos e sistemas de vigilâncias mútuas quanto ao exercício desses papéis. No entanto, esses quadros estruturantes podem ser questionados e não completamente exercidos pelos sujeitos, uma vez que eles tanto não conhecem todos os elementos estruturantes das relações como podem entrar em desacordo, ou se sentirem, ou serem identificados como incapazes de exercerem plenamente o que se espera. Os sentidos dos sujeitos são atacados por essas insuficiências e por muitos dos sentimentos de incompatibilidade. Esses sentimentos são tomados de consciência sobre ações em desacordo e fuga das condições estruturantes.

Velho (1989) observa que, em relação à incompatibilidade das formas de agir e se mostrar de alguns sujeitos em relação a um quadro estrutural cultural (e/ou institucional), projetos de vida em desacordo são capazes de se afastarem daquelas estruturas que os formaram, buscando interações outras em outros quadros culturais. 0 interessante é que este processo de sair da estrutura não necessariamente se apresenta como radical, mas como um conjunto de momentos e possibilidades que fazem os sujeitos transitarem "para dentro" e "para fora" das estruturas culturais, cujas ações se demonstram como um conjunto de manobras e fugas efêmeras que condicionam representações que servem para manter veladas suas incompatibilidades dentro do quadro cultural primeiro.

Mead (apud Honneth, 2003) também observa certa indeterminação sobre as ações do sujeito e aponta para um conjunto de possibilidades criadas por sua própria subjetividade, que se apresenta incapaz: ou de entender, ou de compartilhar do conjunto de elementos de um quadro estrutural cultural. Esta indeterminação seria aspectos de um "mim" que age no social e de um "eu" que pensa determinado social pelo quadro estrutural cultural, que é um fragmento do mesmo. 0 "mim" age em meio às insuficiências e aos descontentamentos sobre si mesmo em um determinado quadro cultural, agindo no sentido de criar linhas de fugas para dar conta objetiva e significativamente de seus desejos e vontades emergentes. Muitas vezes, isso ocorre no encontro com o outro que possibilita a objetivação daquilo que não compreende exatamente, pois "aquilo" não pode ser apreendido no quadro cultural de referência. Nesse processo de ação o "eu" é como outro que fala para si mesmo e que coloca cautela quanto aos novos processos que decorrem das ações do "mim", que representam um desapego sobre os determinantes culturais primeiros que o formou.

A isso recorre, por exemplo, a formação da identidade estigmatizada vista em Plummer (apud Weeks, 1999), constituída pelos seguintes processos: sensibilização, significação, subculturalização, estabilização. $\mathrm{Na}$ constituição da identidade estigmatizada sobre a homossexualidade, por exemplo, os sujeitos primeiro se sensibilizam que algumas de suas formas de agir e de se mostrar estão em desacordo com os preceitos culturais a que vive (sensibilização sobre a sexualidade em desacordo com os padrões de comportamento de gênero regidos pela heterossexualidade).

No primeiro estágio ele não entende o porquê de suas ações serem rechaçadas por outros sujeitos do mesmo quadro cultural. No segundo estágio, os mesmos sujeitos munidos de atributos discriminatórios, constituídos nas relações do quadro cultural, definem significados sobre os comportamentos do sujeito que age em desacordo (que age por força do "mim"). A significação repercute no aprendizado constituído por "eu" que revela ao sujeito, de forma reflexiva (em relação a determinações estabelecidas pelos outros do mesmo quadro cultural), de que aqueles conjuntos de atos (em relação à homossexualidade a transgressão das formas de agir e de se mostrar referentes aos papéis de gênero, por exemplo) exercidos por "mim" são errados e incompatíveis com uma normalidade "natural" sobre condições de papéis a serem exercidos quanto à sexualidade.

É muito provável que exista um desacordo, durante muito tempo, entre determinantes exercidos pela reflexão sobre "eu" e ações de "mim" a determinado sujeito homossexual. A cada ação de "mim", na possibilidade de gerar vazão ao desejo, ocorre uma reflexão do "eu" sobre os erros e transgressões que isso contém: ou gera um conjunto de sofrimentos; ou um conjunto de táticas que transitam entre quadros culturais diferenciados, ora camuflando ora revelando aspectos da identidade estigmatizada. Assim sendo, os sujeitos são capazes de reconstruir as determinações culturais estruturantes e 
dialogar e transitar entre diferentes contextos culturais. Isso é mais evidente quando o pertencimento a um quadro cultural é incapaz de gerar significados ou gera significados danosos quanto à pessoalidade do sujeito. Essa possibilidade de trânsito pode ser interrompida pela estabilização em outro quadro cultural, como as relações constantes em grupos e lugares frequentados por homossexuais, cujos outros papéis, linguagem, formas de agir e de se mostrar e rituais são rearticulados como formador cultural do sujeito, podendo isso também constituir outras incapacidades de trânsito e diálogo com outros quadros de estruturação cultural.

Nesse sentido, Khun (apud Claros; Viaña, 2009) aponta para aspectos referentes à questão da cultura: elas são incomensuráveis, ou seja, é difícil ocorrer o diálogo de cultura, pois não existe como fazer uma tradução completa sobre elementos de outras culturas. Nem mesmo os sujeitos culturais refletem sobre essa complexidade toda da cultura: eles simplesmente vivem em diferentes situações aspectos determinantes de suas culturas, regidas na relação com outros vigilantes sobre atributos e papéis a serem desempenhados dentro do mesmo quadro cultural. Assim, a tradução cultural se revelaria na possibilidade de o sujeito viver intensamente o quadro cultural de outra cultura, o que significaria que as situações sociais deveriam ser traduzidas pelos parâmetros da nova cultura. Se isso fosse possível a um sujeito, significaria que ele está já imerso numa incomensurabilidade que define atos práticos não reflexivos da segunda cultura que está agindo, tendo perdido a capacidade de agir e produzir performances típicas da sua cultura anterior, que iria definir suas ações em uma determinada situação.

Por outro lado, Wimmer (apud Claros; Viaña, 2009) aponta que a noção de homogeneidade de uma cultura é apenas teórica, pois elas são formadas por transformações paradigmáticas que mudam a definição reflexiva sobre determinadas ações e, por conseguinte, as ações dos sujeitos nessas situações. Assim, todas as culturas são produzidas por conflitos internos, e esses conflitos são gerados pelas ações transformadoras dos sujeitos munidos de experiências e crenças constituídas de contados com outras culturas: são ações de pessoalidades que agem em desacordo com os determinantes culturais, mas, ao mesmo tempo, não fogem de seu quadro cultural. Isso produz a disseminação de desconfortos e inquietações perante os outros sobre os próprios determinantes do quadro cultural.

Se as culturas se apresentam como um conjunto de elementos complexos, que nem os próprios sujeitos culturais as entendem por completo, mas cujos parâmetros são estruturados de forma situacional pela interação intersubjetiva de sujeitos dentro da mesma cultura, significa que sujeitos podem aprender a se portar em situações diferenciadas dentro de outra cultura. Para isso, basta seguir os incompletos quadros de referências comportamentais de outros sujeitos nos momentos das interações específicas. Essa capacidade de agir em determinadas situações construindo um quadro de referência situacional intersubjetivo significa que as diferentes pessoalidades são capazes de aprender outros significados quando estes são necessários para se chegar a um acordo e a uma comunicação mútua. Claro que isso se refere a uma necessidade e predisposição dos sujeitos para o acordo e uma abertura de consciência para o entendimento, não funcionando em relação a uma postura consciente de negação e preconceito quanto aos novos parâmetros daquela situação e conjuntos de ações que observa.

Além disso, se as culturas são produtos de contradições e conflitos internos, significa que elas são entidades abertas a novas influências e, por conseguinte, a novos debates culturais e paradigmáticos. Esses debates são trazidos pelos próprios sujeitos dentro de um quadro cultural específico, que refletem sobre o que aprendem com novas experiências culturais. Cabe, assim, às práticas de interculturalidade zelar e promover essa capacidade individual de encontrar em outros quadros culturais respostas a determinadas situações diárias, exercitando a abertura dos sujeitos em relação a novas práticas culturais em situações inusitadas do cotidiano. Pensamos que essa capacidade de relativização não desconstrói o quadro cultural anterior do sujeito, mas permite a ele levar ao seu quadro cultural primeiro experiências novas que entrem em conflito com uma suposta rigidez cultural de seus semelhantes. Essa geração de conflitos permite a possibilidade da experimentação de outras culturas e, assim, a tão possível interculturalidade.

\section{A fenomenologia como metodologia importante aos diálogos culturais}

Pensamos que a fenomenologia pode ser uma metodologia importante nas atividades de pesquisa e extensão que intuem discutir e agir na promoção do encontro e do diálogo entre alteridades, principalmente na sua máxima de "voltar às coisas mesmas" ou na redução fenomenológica. Para Delruelle (2009, p. 300), redução pode ser vista de duas maneiras:

Como operação de reduzir a coisas (uma paisagem,
uma mesa, uma forma geométrica etc.) à sua dimensão
essencial, fundamental - que a de ser um fenômeno;
e também, mais justamente, como operação de a
reconduzir ao seu sentido originário. A redução não
é, pois, uma restrição ou uma diminuição, mas uma
renovação do olhar que lançamos sobre o mundo. 
Isso se refere a uma operação intelectual denominada como épochè fenomenológica, que implicaria gerar dúvida e colocar em suspensão os juízos sobre as coisas e os seres. Para Morão (s./d.) esse processo se caracteriza como um ego filosofante que coloca em dúvida a existência das coisas, mais ainda, a busca pelas ideias que tornaram essa existência naturalizada. Segundo Husserl (s./d., p. 6-7):

Por conseguinte, esta inibição universal de todas as tomadas de posição frente ao mundo objetivo, à qual damos o nome de épochè fenomenológica, torna-se justamente o meio metódico pelo qual me aprendo puramente como aquele eu e aquela vida da consciência na qual e para a qual todo mundo objetivo é para mim, e é tal qual para mim é. Tudo que é mundano, todo ser espaçotemporal é para mim em virtude de o experimentar, percepcionar, recordar, de algum modo pensar, julgar, valorar, desejar etc. Tudo isso é designado por Descartes, como se sabe, como título de cogito. 0 mundo é em geral para mim apenas o que existe conscientemente e para mim vigora em tais cogitationes. Dessas cogitationes recebe ele todo o seu sentido e toda a sua vigência de ser. Nelas recorre toda minha vida mundana. Não posso viver, experimentar, pensar, valorar e agir em outro mundo que não tenha o sentido e a validade em mim próprio. Se me elevar acima de toda esta vida e me abstiver de toda a realização de qualquer crença no ser, a qual supõe justamente o mundo como existente, se dirigir exclusivamente o meu olhar para esta própria vida enquanto consciência do mundo, então ganha-me a mim como ego puro com a corrente pura das minhas cogitationes.

Esta é uma operação básica para conseguir se chegar a uma pretensa interculturalidade ou, mais ainda, a uma relação entre sujeitos diferentes, munidos de identidades e culturalidades diferentes. Para entender as práticas culturais de um grupo ou as formas de ser e agir de um "outro" sujeito, uma alteridade, "eu" tenho que me abster "das minhas cogitações". Nesse sentido, tenho que operar me abstendo "de meus hábitos e de todas as minhas evidências para descobrir a evidência primeira" (Delruelle, 2009, p. 301). Como operação metodológica a isso temos a possibilidade da descrição fenomenológica como "descrição desinteressada" (Delruelle, 2009, p. 302), procurando uma multiplicidade de pontos de vista, buscando entender uma diversidade de variações imaginárias sobre "a coisa" ou o "ser" que se mostra: os múltiplos ângulos e as múltiplas formas que outros, e também outras teorias e formas identitárias, também o entendem. 0 processo implica chegar à percepção sobre a pureza daquilo que vemos, pois "ser" e "coisa" não são simplesmente definidos por determinados olhares sobre eles, regidos pela simplicidade das cogitações. A perspectiva metodológica da descrição na relação das sucessões imaginárias constrói, destrói e reconstrói cogitações sobre os seres e as coisas, possibilitando o pensar profundo sobre as tomadas de entendimento sobre os outros e tornando evidente que esses entendimentos são meras imaginações simplistas contidas em um "ego" restrito, que vê somente o que entende e a partir de como se construiu para entender (o fechamento cultural).

Segundo Delruelle (2009), esse esforço metodológico da fenomenologia em multiplicar os pontos de vista implica um esforço em abrir-se ao ponto de vista de outrem, processo tão sonhado nas discussões sobre possibilidade de agir e promover interculturalidades. Sartre (2010b) e Delruelle (2009, p. 311) nos ensinam que toda consciência é consciência de alguma coisa que não é ela mesma: isso constitui o princípio de intencionalidade. Nesse sentido, em seu artigo traduzido em 2010 "A transcendência do ego - esboço de uma descrição fenomenológica", Sartre nos explica que, comumente, temos consciência da "coisa" que não é ela mesma, assim como temos consciência de um ego que nos é exterior. Assim, a operação necessária é distinguir essa consciência do "eu" para tornar limpa a consciência de um "eu" formado e formador da visão de mundo, na qual restringe a visão e o entendimento do sujeito sobre as coisas, sobre os "outros", sobre os fenômenos. 0 ego se apresentando como uma entidade exterior poderá ser questionado nas intimidades do próprio sujeito. 0 propósito é torná-lo transcendente fora das determinações da épochè como sintoma fundante de "minhas" cogitações. O ego deve ser colocado fora da consciência para limpar a consciência. Deve-se então ter-se consciência do ego transcendente (exterior, fora de minha consciência, na busca da formação da consciência pura, não determinada pelo cogito do ego). Isso pode promover o conflito sobre "minhas" próprias concepções e cogitações restritas, numa ação consciente de experimentar as múltiplas facetas da realidade, sem apegar-se a identidades fixas, na busca de uma descrição aberta as múltiplas imaginações.

Esta esfera transcendental é uma esfera de existência absoluta, isto é, uma esfera de espontaneidades puras, que nunca são objetos e que se determinam elas próprias a existir. 0 "Mim", sendo objeto, é evidente que nunca poderei dizer: minha consciência, isto é, a consciência de meu "Mim" (salvo em um sentido puramente designativo, como quando se diz, por exemplo, o dia de meu batismo). 0 Ego não é proprietário da consciência, é objeto dela. Seguramente nós constituímos [instituímos] espontaneamente nossos estados e nossas ações como produções do Ego. Mas nossos estados e ações são igualmente objetos. Nós jamais teremos intuição direta da espontaneidade de uma consciência instantânea como produzida pelo Ego. Isso é impossível. É apenas no plano das significações e das hipóteses psicológicas que nós podemos conceber uma produção semelhante - e esse erro não é possível senão porque neste plano o Ego e a consciência são visados no vazio. Nesse sentido, se se compreende o "Eu penso" de uma maneira a fazer do pensamento uma produção do Eu, já se constituiu o pensamento como passividade e estado, isto é, como objeto; abandonouse o plano da reflexão pura, no qual o Ego aparece, sem dúvida, mas no horizonte da espontaneidade. A atitude reflexiva é exprimida corretamente pela famosa frase de Rimbaud (na carta do vidente): "Eu é um outro". 
O contexto prova que ele simplesmente quis dizer que a espontaneidade da consciência não saberia emanar do Eu, ela vai em direção ao Eu, ela o encontra, ela deixa-o entrevisto sob sua espessura cristalina, mas ela se dá sobretudo como espontaneidade individuada e impessoal (Sartre, 2010b, p. 223).

Nesse sentido, Delruelle (2009) nos inspira a leitura da obra de Sartre (2010) sobre o existencialismo. Segundo estes autores o homem primeiramente é um "nada" e, sendo assim, a consciência é puro movimento e espontaneidade: mais prática que teórica; ação antes de teoria. Em outra obra, 0 ser e o nada, Sartre (1997) argumenta que os sujeitos criam imagens sobre si mesmos, como condições de um "ser" no futuro, determinadas por conjuntos "de formas de ser" impostas em situações diferenciadas em seu cotidiano (socializadas como boas, belas, eficientes e dignas de admiração). Nesse sentido, "o ser é um ser que procura ele próprio não ser, que nunca é igual a si mesmo, que nunca está presente em si mesmo, pois todo seu ser se define pelo que poderia ter sido, pelo que será etc." (Sartre apud Delruelle, 2009, p. 314).

Assim, em nossas ações cotidianas, somos algo que não queremos ser, pois o que queremos ser está condicionado por uma consciência do que queremos ser, em um futuro próximo. Nossas vidas estão relacionadas a projetos (Velho, 1989) inacabados, pois agimos nas eventualidades das interações cotidianas, como se não fôssemos, mas cujas eventualidades ativam certos preceitos adquiridos pela socialização e a instituição do social, negando este não ser e instaurando uma imagem de mim (sobre como deveria ser e como teria que ser à frente). Esses sentidos se apresentam como importantes à necessidade de desconstrução dos parâmetros de cultura que regem as avaliações sobre "como eu deveria ser" e "como deveriam ser os outros". Isso implica a promoção da liberdade porque, quando não estamos sendo, somos jogados a um projeto pessoal de ser alguma outra coisa. Esse jogo para o futuro é condição do aprendizado entre aqueles que convivem, num círculo de formação cultural, assim como projeto de socialização de instituições sociais e, muito hoje, projeto de manipulações culturais informacionais que ditam certas formas de ser para promoção do consumo. Assim, segundo Sartre (apud Delruelle, 2009, p. 316), o meu ser define-se pelo olhar que o outro lança sobre mim e deixa-se objetivar-se por ele. Nesse sentido, o inferno, segundo este autor, é uma condição em que "os homens se espiam constantemente uns aos outros e procuram incessantemente a consideração dos outros".

É necessário, então, introduzir "o nada" no ser (a aceitação sobre o "não ser" e negação sobre as condições "de ser" - um questionamento sobre as condições "em que se deve" e "como se deve ser"), recusando-se então a se "cristalizar num papel ou numa personalidade determinada pelos outros" (Delruelle, 2009, p. 317). A consciência deve se manter pura em direção ao mundo, de forma fragmentada e não homogeneizada e fixa a um conjunto de parâmetros sobre como devo ser. Assim o sujeito poderia recusar-se a permanecer no seu lugar e, segundo Sartre, aceitar e achar interessante a ideia de manter-se "fora de si", de estar sempre em movimento e de se manter sempre em defasagem sobre o que querem que ele seja.

Essa é uma pista interessante aos processos de interculturalidade que representa justamente uma contradição sobre a ideia de fechamento cultural e a prática cotidiana de restrição do olhar sobre os outros e sobre si mesmo. A ideia de negar a necessidade de sermos algo vai de encontro à liberdade de aprendermos, nos engajarmos nas situações inusitadas e nos envolvermos entre outros presentes diferentes. A aceitação de nossa defasagem em relação a que devemos e queremos ser gera uma possibilidade de sermos o que somos no presente e de aceitar como os outros também estão sendo. Negar nossas imaginações sobre como poderíamos ser e aceitar a condição de não ser ou não estar sendo apresenta uma possibilidade de também entender o outro, como também uma unidade inacabada e defasada, como não sendo aquilo que esperávamos dele, aceitando sua liberdade de não estar sendo como queríamos que ele fosse. Essa postura nos torna atentos à liberdade dos outros serem não sendo. A possibilidade de aceitar os outros não sendo torna possível nossa compreensão sobre outras possibilidades de ser e de admirar essas outras possibilidades de ser. Esta se apresenta como uma pedagogia importante nas relações interpessoais.

\section{Considerações sobre o espaço como provedor da interculturalidade entre sujeitos}

Isso aponta também para uma visão propriamente incompleta sobre as relações contidas no espaço, numa proposta de ação de libertação das amarras definidoras das ações e comportamentos dos outros no espaço. A ideia é que o espaço é encontro das diferenças, cujos outros e eu mesmo não somos exatamente como querem os parâmetros relacionais que, teoricamente, são impostos por condições espaciais hegemônicas de socialização. Esse debate adentra a necessidade de pedagogia da liberdade das formas de agir e se mostrar no espaço, seja ele público ou a determinados espaços institucionais. como a escola, por exemplo. Ninguém é na verdade e todos apresentam insuficiências quanto às necessidades de ser que regem determinado espaço.

Essa visão sobre as insuficiências de ser possibilita a emergência da autenticidade de ser aquilo que não é 
e critica os determinantes contidos nas relações que querem definir certos preceitos de ser. Assim, o encontro das diferenças negam certas exigências de ser no espaço. O espaço é uma condição de encontro de "estórias até agora", conforme Massey (2009), mas também podemos dizer que o espaço pode ser uma condição de um conjunto de projetos de ser que, na verdade, não são. As condições são paradoxais: o espaço é um conjunto de "estórias até agora", nesse sentido, defasadas quanto à necessidade de ser em determinado espaço. Essa condição de não ser no espaço gera a incapacidade de se gerar padrões de ser no espaço, sendo ele, assim, encontro da diferença que "não é o que devia ser" que gera "autenticidades novas de ser" ante "aquelas que deveriam ser".

O conflito se dá em duas frentes: um conflito pessoal íntimo sobre "a consciência de que não está sendo" e uma "necessidade de se projetar sendo"; um conflito interpessoal perante "aqueles que objetivam os sujeitos a ser", mesmo, esquizofrenicamente, "não estar sendo". 0 primeiro conflito solapa a autenticidade e criatividade "do ser que não está sendo" (está sendo algo contextual, espontâneo e criativo). 0 segundo conflito reprime o diálogo entre as diferenças que ricamente "não estão sendo" e que poderiam crescer juntas em relação a "múltiplas possibilidades criativas de estar sendo" e de "estar aprendendo a ser diferente" e de dialogar com essas possibilidades de diferenças.

Nesse sentido, o propósito é criar uma consciência pura e livre quanto à "autenticidade de estar sendo do ser" e uma "libertação das nossas projeções de como eu e os outros devem ser". Em primeiro momento, as relações espaciais devem promover a "noção que o ser é o nada" e "que ser nada é positivo" em termos que abrir-se ao novo e as novas experiências. Essa visão de que "sou nada", em relação ao que se coloca na multiplicidade de autenticidades inacabadas em relação, torna-me menos rígido em julgar outrem e passível de aceitar suas formas de expressão inacabadas em relação ao que "eu" desejo dele. Essa pedagogia da autenticidade é muito necessária hoje em espaços de convivência de uma diversidade de sujeitos e na visão da incapacidade das regras sobre comportamentos, porque mesmo aqueles que ditam determinadas regras sobre "como os outros devem ser" "apresentam-se sempre incapazes efetivamente de ser". Caso estes se apresentem efetivamente "capazes de ser o que se deseja ser", isso representa um abafamento sobre as múltiplas possibilidades de ser algo diferente e criativo.

Os estudos sobre Geografias Queers e feministas na atualidade, no Brasil sendo muito desenvolvidas por Joseli Maria Silva (vide Silva, 2009), apontam para análises sobre interações sociais que se traduzem em relações espaciais situacionais que diferenciam e rearticulam diferentes atributos identitários dos sujeitos. Nessa perspectiva, o espaço se dissolve em múltiplas condições relacionais singulares, nas quais certos padrões identitários e de papéis sociais institucionalizados ora se reforçam, ora se desestruturam em diferentes situações sociais. Assim, espacialidades diferenciadas articulam inúmeras formas e configurações de poder localizadas, regidas situacionalmente, que estabelecem posições diferenciadas dos sujeitos entre "centros" e "margens" de "poder-fazer" e "poder-influenciar" outros.

Énesse sentido que o espaço deve ser compreendido de forma "relacional", e isso implica "reconhecer as relações entre as pessoas marcadas por diferenciações sociais que constituem suas identidades permanentemente confrontadas socialmente, cuja espacialidade é um dos elementos dessa construção" (Silva; Ornat, 2012, p. 54). Para os sujeitos, o espaço social é constituído de inúmeras "possibilidades" e "interdições" relacionais, em diferentes níveis fenomênicos (baseados na perspectiva singular dos sujeitos sociais) de possibilidade de se relacionar com "outros" situacionalmente localizados. Nesse sentido, as realidades interculturais são realidades espaciais situacionais, nas quais diferentes atributos dos sujeitos entram em "jogo" na interação, que são negociadas frente a uma "aura" localizada de poder relacional, que estabelecem sistemas de valorações simbólicas e existenciais coletivamente articuladas no decorrer da prática social.

Essas confrontações existenciais em determinadas espacialidades são relacionadas a condições identitárias "interseccionalizadas" (Crenshaw, 2002) "atravessadas" por diferentes atributos evidenciados socialmente, como gênero, classe, raça, sexualidade, idade, lugar de residência, expressão estética etc. - -, nos quais os sujeitos se tornam singulares em cada realidade socioespacial que convive (ou que apresenta dificuldade de conviver). Na perspectiva da "interseccionalidade" (MacCall, 2005; Williams, 1994), os sujeitos apresentamse múltiplos, porque suas convivências sociais articulam diferentes características de "si mesmo", sendo ora valoradas, ora desvalorizadas em diferentes espaços relacionais. Isso gera, assim, mapas existenciais de diferentes "possibilidades" e "interdições relacionais" em múltiplas espacialidades geradas pelas experiências cotidianas dos sujeitos sociais.

Nesse sentido, conforme Silva e Ornat (2012, p. 56), o espaço enquanto identidade "essencializada" e "prédiscursiva" não existe porque ele é conformado por relações interseccionais, sendo dinâmico na perspectiva da posição dos sujeitos confrontados diretamente na relação social localizada espacialmente, cujas suas identidades apresentam-se paradoxalmente valoradas e desvalorizadas. Assim, o espaço constitui e é, ao mesmo tempo, constituído pelas relações 
sociais situacionais, definidos por diferentes "estórias até agora" dos sujeitos sociais, cujos valores e "desvalores" sociais institucionalizados apresentamse ora reforçados ora desconstruídos em diferentes perspectivas de entendimento e articulação simbólicas expressos nas práticas coletivas do "aqui e agora" das interações situacionais. Esses sistemas de valorização e desvalorização organizam "posições" diferenciadas dos sujeitos na interação social, colocando alguns no "centro de comando" perante outros "à margem desse comando". As diferentes gerações de comando são organizadas pelos jogos e negociações que trazem à tona atributos interseccionais dos sujeitos que interagem na situação.

O espaço interacional situacional, assim, é criador das perspectivas existenciais dos sujeitos, pois tais experiências diferencias constroem muitas das definições sobre os "outros" e sobre "si mesmos", causando sérios impactos em suas subjetividades e psiques, assim como capacidades múltiplas de "agir" e de "se mostrar" em outros lugares ou espaços relacionais. As interações geradas em espaços relacionais produzem capacidades diferenciadas de articulação íntima das identificações dos sujeitos sociais, assim como de seus entendimentos sobre os "outros sociais", e os colocam em diferentes possibilidades de mobilização de seus corpos e geração de relações. É nesse sentido que as espacialidades construídas por "estórias até agora", em localizações "aqui e agora", geram os diferentes tempos e os diferentes espaços futuros dos sujeitos sociais, porque o que se revela no futuro é construído pelo espaço relacional presente, na construção das capacidades e incapacidades dos sujeitos regidos pelas relações sociais situacionais. Os espaços, assim, são atributos pessoais e socialmente construídos, em constante produção e transformação (Massey, 2009), pois assim são as relações dos sujeitos sociais em constante processo de transformação em virtude das complexas relações interculturais regidas por suas experiências pessoais em interações coletivamente organizadas de forma situacional.

\section{Considerações finais acerca da Geografia}

Como percebermos nas discussões, os processos interculturais, principalmente na perspectiva de Sartre, remetem a condições existenciais singulares dos diferentes sujeitos sociais e suas relações situacionais localizadas. Não estamos trabalhando exatamente com sujeitos portadores de cultura em relação a suas interações com outros sujeitos portadores de "outras" culturas, mas de sujeitos cujas suas alteridades estão/ são interseccionalizadas em diferentes contextos socioespaciais de interações sociais. Esses contextos e situações socioespaciais de interação evidenciam as condições interseccionais dos sujeitos sociais, e isso produz uma "cultura localizada e situacional", composta por condições simbólicas e práticas "centrais" e "marginais", posicionando diferenciadamente os sujeitos na interação. É nesse sentido que a Geografia deve se abrir a novas noções de "ser" e "estar" no espaço, no sentido de trabalhar pela evidência e a aceitação sobre a multiplicidade de existências espaciais, não para aprisionar e fixar certas representações espaciais e certas identidades estanques dos sujeitos sociais, mas para entender os processos múltiplos de negociação de existência e de identificação em coletividades socioespaciais diferenciadas.

Assim como Maffesoli (2002) nos fala de uma "sociologia du dedans", podemos pensar em uma Geografia du dedans ("de dentro" - das situações socioespaciais cotidianas), pois além dos dados sobre os grupos sociais há uma dinâmica própria só observada pela aproximação e pela vivência das trajetividades e das situações de interação dos sujeitos inseridos em grupos singulares. Isso, nesse sentido, remete a uma crítica à própria verticalização do conhecimento que explica as situações sociais (que geram preconceitos e estereótipos acadêmicos) e gera uma necessidade de trazer à tona os próprios argumentos explicativos daqueles com quem nos interessamos em trabalhar. Nesse processo o sujeito pesquisador deverá se transformar com os sujeitos pesquisados e com a realidade vivenciada, no sentido de colocar em xeque suas definições e estereótipos sobre a realidade pesquisada. 0 "truque" principal é sempre desconfiar de algumas conclusões e algumas explicações obtidas, procurando aprofundar em número e qualidade o conhecimento sobre o universo pesquisado, como um processo de pesquisa que constantemente desconstrói uma evidência tornada clara.

A Geografia que queremos conceber, assim, aponta para a ocorrência de políticas múltiplas de usos e relações espaciais, nas quais as explicações sobre os sujeitos e seus espaços se apresentam como novos pequenos universos singulares de trocas, negociações e jogos de identificações e de usos de pequenos poderes. Para esta Geografia teremos que nos aprofundar nas práticas de pesquisa participativas e nas ações junto aos sujeitos pesquisados, no sentido de nos tornarmos sujeitos simples isentos de um "saber-fazer" e um conhecimento hegemônico "sobre" aquilo que acontece nas diversidades de intermédios do espaço social. 
BENJAMIN, W. (2004). Charles Baudelaire: um lírico no auge do capitalismo. Obras escolhidas III. 4. ed. São Paulo: Brasiliense.

CANCLINI, N. (1998). Culturas híbridas: estratégias para entrar e sair da modernidade. São Paulo: EDUSP.

CLAROS, L.; VIAÑA, J. (2009). La interculturalidad como lucha contrahegemónica: Fundamentos no relativistas para una crítica de la superculturalidad. In: MORA, David (org.). Interculturalidad crítica y descolonización: fundamentos para el debate. La Paz, Bolívia: Instituto Internacional de Integración del Convenio Andrés Bello (III-CAB).

CRENSHAW, K. (2002). Documento para o encontro de especialistas em aspectos da discriminação racial relativos ao gênero. Revista Estudos Feministas. Ano 10. Florianópolis: primeiro semestre.

CRENSHAW, K. (1997). Mapping the Margins: Intersectionality, Identity Politics, and Violence Against Women of Color. In: MARSCKE, Karen J. The legal response to violence against women. Garland Publishing, Inc. New York \& London. Google Books: acesso em junho de 2016.

DELRUELLE, E. (2009). Metamorfoses do sujeito: ética filosófica de Sócrates a Foucault. Lisboa: Instituto Piaget.

FEATHERSTONE, M. (1995). O desmanche da cultura: globalização, pós-modernismo e identidade. São Paulo: SESC; Studio Nobel.

FORTUNA, C.; SILVA, A. S. (2002). A cidade do lado da cultura: espacialidades sociais e modalidades de intermediação cultural. In: SANTOS, B. de S. (org.). A globalização e as ciências sociais. São Paulo: Cortez.

GEERTZ, C. (1989). A interpretação das culturas. Rio de Janeiro: LTC.

GOFFMAN, E. (1988). Estigma. Rio de Janeiro: Ed. Guanabara.

(1996). A representação do eu na vida cotidiana. Petrópolis: Vozes.

GROFF, P. V.; PAGEL, R. (2008). Multiculturalismo e direitos humanos: direito para as minorias. In: TEDESCHI, L. A.; RAMOS, A. D.; SILVA, A. L. F. da; KNAPP, C.; FERREIRA, B. (orgs.). Abordagens interculturais. Porto Alegre: Martins Livreiro Editor.

HONNETH, A. (2003). Luta pelo reconhecimento: a gramática moral dos conflitos sociais. São Paulo: Editora 34.

HUSSERL, E. (s./d.). Conferência de Paris (1929). Tradução Artur Morão e Antonio Fidalgo. Lisboa: Luso Sofia Press. Disponível em: <http://www.lusosofia.net/textos/husserl_conferencias_de_paris.pdf>. Acesso em: outubro de 2013.

MACCALL, L. (2005). The Complexity of Intersectionality. In: Signs: Journal of Women, Culture and Society, 30 (3): 17711800. Chicago. Disponível em: <http://socialdifference.columbia.edu/files/socialdiff/projects/Article_\%20The\%20 Complexity\%20of\%20Intersectionality\%20by\%20Leslie\%20McCall.pdf>. Acesso em: junho de 2016.

MACLAREN, P. (1997). Multiculturalismo crítico. São Paulo: Cortez.

MASSEY, D. (2009). Pelo espaço: uma nova política da espacialidade. Rio de Janeiro: Bertrand Brasil.

MATTOS, P. (2006). A sociologia política do reconhecimento: as contribuições de Charles Taylor, Axel Honneth e Nancy Fraser. São Paulo: Annablume.

MORÃO, A. Apresentação. In: HUSSERL, Edmund (s./d.). Conferência de Paris (1929). Tradução Artur Morão e Antonio Fidalgo. Lisboa: Luso Sofia Press. Disponível em: <http://www.lusosofia.net/textos/husserl_conferencias_de_paris. pdf>. Acesso em: outubro de 2013.

OLIVEN, R. G. (1987). A antropologia de grupos urbanos. Petrópolis: Vozes.

SANTOS, B. S. (2003). Reconhecer para libertar: caminhos do cosmopolitismo multicultural. Rio de Janeiro: Civilização Brasileira.

SARTRE, J. (2010). O existencialismo é um humanismo. Petrópolis: Vozes.

(2010b). A transcendência do ego - esboço de uma descrição fenomenológica. Cadernos Espinosanos - Estudos sobre o século XVII. Número XXII. São Paulo: FFLCH-USP.

(1997). O ser e o nada: ensaio de ontologia fenomenológica. Petrópolis: Vozes. 
SILVA, J. M. (2009). Geografias subversivas: discurso sobre espaço, gênero e sexualidades. Ponta Grossa: Toda Palavra.

SILVA, J.; ORNAT, M. (2012). Interseccionalidade e mobilidade transnacional entre Brasil e Espanha nas redes de prostituição. Revista Anpege, Vol. 8, n. 10.

TAYLOR, C. (2000). Argumentos filosóficos. São Paulo: Edições Loyola.

TEDESCO, J. C. (2003). Paradigmas do cotidiano: introdução à constituição de um campo de análise social. Passo Fundo: Edunisc, UPF.

VELHO, G. (1989). Subjetividade e sociedade: uma experiência de geração. Rio de Janeiro: Jorge Zahar.

WEEKS, J. (1999). O corpo e a sexualidade. In: LOURO, G. L. (org.). O corpo educado. Belo Horizonte: Autêntica. 